\title{
The Composition of 'The Depressed Person'
}

\author{
Elliott Morsia
}

\begin{abstract}
Despite having expanded an initial focus upon his most renowned novel Infinite Jest (1996) in recent years, David Foster Wallace studies has yet to broach questions regarding the textual status of Wallace's work. In order to do so, this essay applies the methodology of genetic criticism by studying the composition of Wallace's short story 'The Depressed Person'. Genetic criticism involves the practical analysis of manuscripts or rough drafts with the aim of describing a process of writing, a text's genesis. By treating text as process rather than product, genetic criticism subverts the traditional notion of "the text itself". Wallace's fiction shares a similar resistance to finished products. This is particularly true of the postInfinite Jest phase in Wallace's career, which begins with Brief Interviews With Hideous Men (1999), in which the 'The Depressed Person' is collected, and ends, emphatically, with Wallace's unfinished and posthumously published final novel The Pale King (2011); the text of which exists only in draft form. Using genetic criticism, this essay goes on to consider the relationship between Wallace's writing process and the eponymous depressed person's predicament in the story, considering the significance of these topics within a broader context of modernism and revision.
\end{abstract}

It is beautiful and scary to watch the footnotes get larger and larger with each turn of the page. Everyone here is very high on the story. It's a rare pleasure to feel such a long process come to fruition, at least for me. [. . .] And thanks for letting me do this with you. It is a truly gratifying work. (Conn, unpublished letter)

This letter, written to David Foster Wallace to accompany the galley proofs for 'The Depressed Person' by the story's editor at Harper's Magazine, Charis Conn, provides invaluable insight into Wallace's composition of the story. While the special "high" experienced by Conn and others echoes the special "buzz" Wallace himself experienced when writing, and which is said to have led him to pursue a career as a writer (Boswell 2003, 4; MAX 2012), the letter also refers to the "long process" of composition as having 
"come to fruition" in the production of "a truly gratifying work". It is this suggestion that I would like to begin by considering.

On one level, this relates to Conn's own role in encouraging Wallace's composition and in editing down a much longer initial draft of the story to produce the version published by Harper's in January $1998 .{ }^{1}$ However, the question of establishing a "work" also carries a much broader cultural significance. It is, to a large extent, a necessity for writers, editors, publishers and critics to establish a "work", in a sense ratifying a process of composition. Representing something complete and therefore both accountable and marketable, the work also satisfies a conventional notion of what an aesthetic object actually is (a finished product). Aside from the requirement to comply with a set of conventions, there are further, human motivations for establishing a work, which include its role as crowning achievement, as well as satisfying a basic human desire for closure. Whether art actually fulfils this promise is another question, however, and one might well argue that art precisely resists and denies us closure by evading, outgrowing or outliving its apparent boundaries.

Furthermore, while a finished product may be seen to prevent (or liberate us from) the tyranny of a potentially endless process, the promise of a unifying telos can itself become a burden. Consider Marshal Boswell's suggestion that the modernist quest for "newness and innovation, for further refinement and complexity", which is linked with "an implicit faith in the possibility of perfection, in the achievement of an end", also "sets artistic development on a road to death, affirming an endpoint that is, in the final analysis, a zero-point. ... All of which begs the question, What is one to do next?" (Boswell 2003, 11). ${ }^{2}$ This question is especially pertinent to Wallace who, following the critical acclaim surrounding Infinite Jest (1996), worked on his final novel The Pale King (2011) for at least a decade without attaining an "endpoint". Leaving the author's untimely death to one

1. Following the story's growth/expansion from an initial 406-word fragment, through various drafts reaching a length upwards of 10,000 words, the editorial process can be quantified in terms of its reduction down to a version of less than 7,000 words in length for publication in Harper's Magazine; for the story's inclusion in Brief Interviews With Hideous Men (1999) the following year, Wallace returned to the drafts and it expanded beyond 10,000 words in length once again.

2. Boswell draws this description from Matei Calinescu's discussion of modernity in The Five Faces of Modernity (1977), but I would suggest it is inadequate for modernism, which is often seen as a critique of modernity; according to this description, D. H. Lawrence, for example, would be seen as an anti-modernist. 
side, The Pale King seems to resist, intrinsically, the notion of an end- or zero-point, both in its formal organization (or disorganization) and in its meandering narrative content. This resistance is echoed across Wallace's later work (particularly post-Infinite Jest, whose reception led Wallace to sense his own establishment in the canon) and is evident throughout Brief Interviews With Hideous Men (1999), in which 'The Depressed Person' is collected. ${ }^{3}$

Before moving on to consider "such a long process" of composition for 'The Depressed Person', it is worth making a brief note on genetic criticism, as its text-critical framework differs from that of traditional Anglo-American literary criticism. ${ }^{4}$ While author-centric approaches to literature have received overlapping critiques from both modernist and post-modernist perspectives (from the "Intentional Fallacy" to the "Death of the Author"), these newer theories of interpretation continue to rely upon a single fixed text, which they adopt as object of study. ${ }^{5}$ In contrast, genetic criticism studies a process of writing, favouring the act of writing over the written object, which establishes new ground for the author in literary interpretation, as the main agent in a process of writing. ${ }^{6}$ While Anglo-American literary criticism can be seen to produce the following series then: draft or early version, intentionality and intertextuality, the text, genetic criticism produces the following series: avant-texte, texts, writing process.

The term "avant-texte", with which genetic criticism begins, is used to denote all the written materials that come before and contribute toward an established work, once organized and arranged by the critic. As these materials will not have existed in this arrangement beforehand, the avanttexte is a product of critical work (a critical construction). However, while the avant-texte contains a synchronic array of texts (a textual system), the main interest of genetic criticism is in the diachronic writing process, which can be reconstructed via its manifestation in the drafts.

3. The collection includes a number of deliberately "unfinished" story cycles, as well as individual stories such as 'Death is Not the End', which concerns the unproductive lethargy of a fictional Nobel laureate poet.

4. For a fuller introduction see Ferrer, Deppman and Groden 2004.

5. For a non-genetic critique of this object see PAR Ker 1987.

6. Almuth Grésillon suggests manuscripts, the objects of study for genetic criticism, provide "a place where the question of the author can be studied in a new light: a place of significant conflict, a place of the genesis of the author" (Grésillon 1997, 123). 


\section{The Intersection of Genetic Criticism and Wallace Studies}

Following a number of short and sporadic academic studies of Wallace's work in the 1990s (articles and book chapters, usually discussing Wallace in conjunction with other contemporary US writers), 2003 represented a landmark year for the emergence of Wallace studies. It saw the publication of both Marshall Boswell's Understanding David Foster Wallace, the first major study of all Wallace's writing up to that date, with Infinite Jest serving as the "career-making book", as well as, fittingly, Stephen Burn's A Reader's Guide to Infinite Jest (Boswell 2003, 9). A flurry of new scholars and students continued to complete work on Wallace's fiction and non-fiction in the 2000s, reflected by the more recent collection edited by David Hering, entitled Consider David Foster (2010). Following this collection, the first full biography of Wallace also appeared, entitled Every Love Story is a Ghost Story (2012) and written by D. T. Max. Given the earlier novel's length and acclaim, as well as the fact that Wallace's editorially constructed final novel The Pale King did not appear until 2011, Infinite Jest has understandably held sway over Wallace's legacy. A decade on from the first landmark year in Wallace studies though, Boswell and Burn co-edited A Companion to David Foster Wallace Studies (2013), which sought "to redress the balance with detailed readings of each book of fiction" and aimed "to consolidate where Wallace studies stands after all the novels have been published", thus "fill[ing] out this skeleton history of Wallace criticism" (Boswell and Burn 2013, ix-xii). Despite this progress, Wallace studies have yet to percolate down to the textual level and genetic criticism offers a timely development in this respect.

At present, it is difficult for readers or critics to grasp even the basic chronology behind the creation of much of Wallace's work. In a recent chapter on Brief Interviews with Hideous Men, Mary K. Holland, surveying existing studies in a footnote, has noted that book chapters by Marshall Boswell and Zadie Smith provide "the only concerted considerations" of this collection to date (Holland 2013, 128), although Holland's own chapter can now be added to this list. All three of these chapters treat Brief Interviews as a whole. As a result, they neither "zone in" on individual stories, nor do they explore specific texts beyond their face value appearance. Of 'The Depressed Person', for example, although Holland notes that the story "was published initially in Harper's [in 1998]", the essay overlooks the 
fact that this publication represents an alternate version and is significantly different from the one published in Brief Interviews (Holland 2013, 116). ${ }^{7}$

Holland's essay is similarly limited in its account of the collection as a whole, with another footnote explaining that "of the 20 noninterview stories, Wallace published all but 2 [ . . ] prior to the collection" - the earliest "in 1991" — and of the 18 interview stories, "Wallace published 9 [. . .] one in 1997, seven in 1998, and another in 1999" (Holland 2013, 128). ${ }^{8}$ This publication history provides only general hints as to the underlying composition of the book, and its placement in footnotes is also indicative of the commonly held view among literary critics that textual research is of marginal use (or is only within the remit of editors or bibliographers).

Greater "textual awareness" (VAN Hulle, 2003) not only contributes towards our historical knowledge of texts, but it also encourages critics to enquire into the writing processes that engender them, as in genetic criticism. Such enquiry expands a critic's range for interpretation, while also offering new insights into existing materials. Holland indicates as much at the end of her footnote by noting how:

This publication history [for Brief Interviews] suggests that the interview format that shapes and helps unify the collection came late in a writing process that had already produced a formally diverse body of texts over several years. (Holland 2013, 128)

This insight clearly contains implicit hermeneutic repercussions, but these are only hinted at in this summary. By zoning in on 'The Depressed Person', one of several stories in Brief Interviews that separates out from the main story-cycles in the volume, this essay begins to dig beneath the surface. ${ }^{9}$

7. For example, the earlier version is less than two thirds in length compared to the later one; I discuss the different versions in detail in this essay.

8. The two previously unpublished stories include "Forever Overhead" and "Church Not Made with Hands", at least one of which was originally composed in the previous decade, along with the stories collected in Girl With Curious Hair.

9. These cycles include the eponymous interview series itself ("Brief Interviews With Hideous Men") as well as "Yet Another Example of the Porousness of Certain Borders" and "The Devil is a Busy Man". 


\section{"How was she to decide and describe ... what all she'd so painfully learned said about her?"}

'The Depressed Person' began life as a short story of barely two pages in length, written in felt-tip pen and amounting to just 406 words. Alongside a familiar original title, 'A Depressed Person', revised to 'The Very Depressed Person', the first draft fragment began with familiar lines:

The depressed person was in terrible pain, and the impossibility of that this pain's articulation was part of the pain. Despairing of describing the pain or conveying the utterness of it to those around her, the depressed person instead described thousand[?] circumstances that were painful. Her parents, who had divorced when she was a child, used her as a pawn in the games they played. She had, for instance, required orthodonture $\ldots(\text { Wallace MS1, } 1)^{10}$

Before providing a breakdown of the overall compositional history of the story and detailing the various draft levels and extant manuscripts, an initial overview of Wallace's writing process for 'The Depressed Person' can be gained by following what happens to these initial lines through the story's various drafts. If we begin by isolating the first sentence, we can produce the following series, taken from the most substantial drafts of the story:

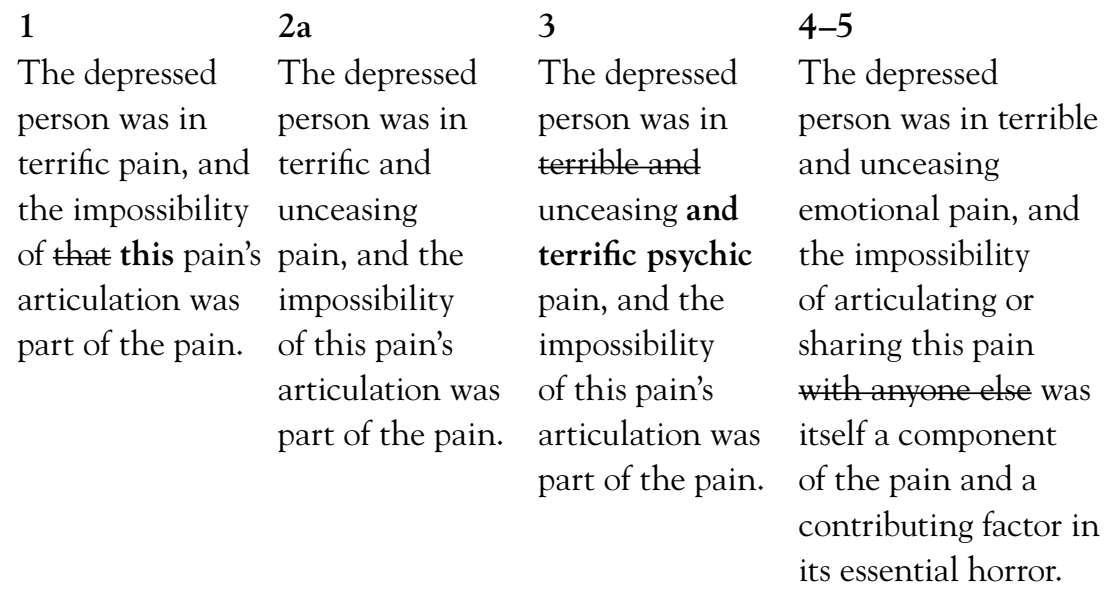

10. Note on the Transcriptions: In the presentation of manuscript text in this essay, strikethroughs indicate words deleted (deted), bold font indicates words inserted (inserted), and superscript indicates words inserted super-lineally (inserted super-lineally). 
An initial typology for Wallace's composition can be produced on the basis of the evolution of this sentence, containing three major patterns. (1) First is the revision of adjectives or descriptors: the first description in the first sentence of the story - regarding the basic pain of depression, the effort to describe which is one of the main drives in the story-is revised repeatedly:

The depressed person was in terrific

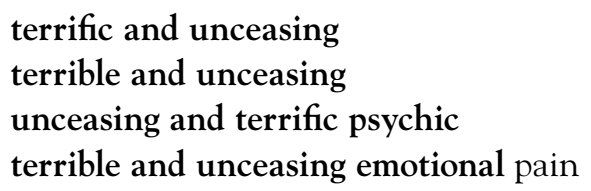

In the course of these revisions, Wallace switches from "terrific" to "terrible", switches back from "terrible" to "terrific", before eventually switching again from "terrific" to "terrible", and we can echo Dirk Van Hulle here in noting that such words, removed and then re-inserted, are subtly other than words that were never called into question (VAN Hulle 2009, 452-3). (2) Second is the insertion of new passages which develop or build upon the shorter original text: the insertion in this instance comes in the fourth draft, where Wallace adds that "the impossibility of that this pain's articulation was part of the pain articulating or sharing this pain with anyone else was itself a component of the pain and a contributing factor in its essential horror", which doubles the text in length at this point and develops the drive to articulate depression. (3) And third is the repetition or re-iteration of words and phrases for clarity or emphasis: in this example repetition occurs within the revision in the tond-fro between "terrific" and "terrible", although the repetition of "pain" three times in the sentence itself, even in the short original, is also noteworthy.

Moving on to the second sentence, each of these features are displayed once more: 
1

Despairing of describing the pain or conveying the utterness of it to those around her, the depressed person instead described thousand[?] circumstances that were painful.

3

Despairing of describing the actual pain or expressing its utterness to those around her, the depressed person instead described past or present circumstances that were possibly somehow related (probably) to the pain, to its etiology and cause, hoping (the depressed person) to at least express to those around her something of the pain's context and texture.

\section{4-5}

Despairing, then, of describing the emotional pain or expressing its utterness to those around her, the depressed person instead described circumstances, both past and ongoing, which were somehow related to the pain, to its etiology and cause, hoping at least to be able to express to others something of the pain's context, its — as it were — shape and texture.

The adjectives for the pain of depression shift from "the pain" to "the actual pain" to "the emotional pain." In the second and third drafts Wallace inserts and then builds upon a new block of text in the second half of the sentence, which doubles the length of the text at this stage: "circumstances that were possibly somehow related (probably) to the pain, to its etiology and cause, hoping (the depressed person) to at least express to those around her something of the pain's context and texture". Finally, repetition/reiteration increases not only through the allusions to pain, but also through the repetitive allusion to "the depressed person" in parentheses; while this particular insertion in version 3 is deleted in the following draft, Wallace introduced parenthetical references to the subject of sentences throughout the drafts and they feature heavily in the final version of the story.

In contrast to the opening two sentences, the third goes almost completely unaltered throughout the many drafts.

1

Her parents, who had divorced when she was a child, used her as a pawn in the games they played.

\section{2-5}

The depressed person's parents, for example, who had divorced when she was a child, had used her as a pawn in the sick games they played. 
This sentence highlights the staying power of the initial material and emphasizes the significance of an early fragment to even the latest draft. Even in these minor alterations though, the same patterns of revision are present: besides the minor syntactic insertion "for example", Wallace has altered "her parents" to the more repetitive "the depressed person's parents", and then in the final draft inserted an adjective to describe the "sick games they played".

Alongside the three patterns discussed so far-revision of adjectives, addition, and repetition - there is a fourth pattern which is not demonstrated in the opening sentences but which does relate to that of addition. Namely, Wallace's habit of writing short notes which are then incorporated into the next draft stage and usually expanded. There is an example of this at the end of the first typescript draft, where Wallace inserted a separate and elliptical paragraph in square brackets entitled "WHY FRIENDS FAR AWAY", which was subsequently incorporated and expanded in the next draft.

Altogether, these four patterns provide an initial guide to Wallace's writing process. However, there is one remaining and highly significant feature in the composition of 'The Depressed Person' that the opening sentences do not flag up, or rather do so only by its absence, and this relates to dialogue. Rather than add a fifth item to the existing list though, "dialogical" revision can be seen as representing a separate type of revision, enabling the previous four features to be grouped as a first type, which I would label "monological". While the first type of revision is evident throughout and appears to be a self-conscious mode for the author, the second type of revision may have been unconscious to the author, but plays a crucial, innovative role in the story's composition.

Dialogical revision demonstrates itself when we track the manner in which the initial fragment, barely two pages in length, exploded open in the second draft, which, at around 15 pages, was not far short of the 20 or so pages in length the story eventually reached. As this involves moving between different draft stages as a whole, however, and considering the overall compositional process, I will first provide an overview of the story's compositional history, giving an account of when and for how long Wallace worked on the story, how many drafts were completed and which materials have survived.

By studying the materials in Wallace's archive and matching them against tangential allusions in Max's biography, we can piece together the following timeline for "The Depressed Person": 
- Spring 1997: Charis Conn, Wallace's fiction editor at Harper's Magazine visits Wallace; probable conception of the story;

- Spring to Autumn 1997: Wallace writes and works on multiple drafts for the story, which originally carried different titles, predominately: 'PROVENIENCE (or, A Depressed Person);'

- September 1997: Wallace receives galley proofs dated 29/09/97 for the December 1997 edition of Harper's Magazine;

- January 1998: 'The Depressed Person' appears in Harper's: pp. 57-64, double-columned, accompanied by 2 illustrations, by Mark Ulriksen (see figure 1);

- April 1999: uncut and revised version of 'The Depressed Person' published in Brief Interviews With Hideous Men.

The drafts for 'The Depressed Person' are housed in Wallace's archive in the Harry Ransom Centre at the University of Texas. There are around 175 pages of material for the story in total and this appears to consist of ten different layers. The first two are handwritten drafts; there are then seven typescripts; and finally one set of galley proofs for Harper's. These layers can be condensed into a smaller number of major writing phases, which I have detailed in the following table:

\section{Writing phase/version:}

Avant-texte

0-1 2 pp., 'A The Very Depressed Person,' handwritten MS, felt-tip pen, light revision

2a-c 15 pp., 'Provenience (or, A Depressed Person),' composite: handwritten MS p. 8 and pp. 12-15, pencil, heavy revision in felt-tip pen (2a); 2-page insert for p. 8 also handwritten MS, felt-tip pen, insertions in same pen (2b); and typescript pp. 1-7, watermarked paper: "Illinois State University", revision in felt-tip pen and biro (2c); MS for pp. 1-7 \& 9-11 appears to be missing

316 pp., 'Provenience (or, A Depressed Person),' typescript, watermarked paper: "Illinois State University", revision in 2 different biros, finishes in medias res

419 pp., 'The Depressed Person,' "Long Version”, very minor alteration in black biro, circa 10,500 words 


\section{Text I/pre-text}

513 pp., 'The Depressed Person,' "7-20-97-4th Round of Editing-6693 Words", no markings

\section{Text II/post-text}

630 pp., 'The Depressed Person,' published in Brief Interviews With Hideous Men (1999), circa 10,500 words: missing a draft tracking the minor alterations between this text and that of 4 or 5

The first draft fragment is handwritten and runs to just 2 pages in length $(0-1)$. The second handwritten draft runs to around 15 pages, but only 5 pages survive (2a), not including a handwritten insertion of 2 pages (2b). The first typescript draft is of a similar length but only 7 pages survive (2c); as these 7 pages correspond to 7 of the 10 pages missing from the second handwritten draft, however, the second handwritten draft and the first typed draft can be combined represent a second major writing phase $(2 \mathrm{a}-\mathrm{c})$. Of the remaining six typescripts, three can be selected to represent the third, fourth and fifth writing phases as the remaining three typescripts simply track the four rounds of editing between Wallace and Conn (between phases four and five) until Wallace finally agreed to cut the text as it had stood at the end of the fourth phase (4: circa 10,500 words), to its shortest length at the end of the fifth (5: circa 6,500 words) for publication in Harper's. The end of phase four, the long version, is close to the text later published in Brief Interviews (also circa 10,500 words), but there are some revisions to the later text, meaning the latest version resulted from a further sixth (and final) compositional phase.

While textual critics highlight the differences between text, work, draft and document (Shillingsburg 1996), it is worth echoing the suggestion by genetic critics that a draft should not simply be seen as an early or incomplete text of a work, but should rather be understood as a type of "protocol for completing a text" (FerRer 1998). ${ }^{11}$ The manner in which Wallace develops his drafts through distinct stages making use of shorthand and annotations is itself highly suggestive of this, as is the use of initial short fragments as a starting point; throughout early drafts for The Pale King, which also began with initial, provisional fragments, Wallace

11. Dirk Van Hulle has also discussed this point (VAn Hulle 2013, 11). 
actually used "Zero Draft" as a header, likewise suggesting that rough drafts are something less or other than "texts". ${ }^{12}$

Besides this shared usage of fragments, the composition of "The Depressed Person" can also be seen as representative (to some extent) of Wallace's writing in general due to the author's own description of his writing methods in a written interview for Amherst (the college magazine) in spring 1999, entitled 'Brief Interview With a Five Draft Man'. Wallace writes:

I am a Five Draft man. I actually learned this at Amherst, in William Kennick's Philosophy 17 and 18, with their brutal paper-every-two-weeks schedules. I got down a little system of writing and two rewrites and two typed drafts. I've used it ever since. I like it. [. . .] the first two of these drafts are pen-and-paper, which is a bit old-fashioned, but other than that I don't think there's anything very distinctive about my work habits. (Wallace 1999)

Although it misses the important editorial exchange with Charis Conn, this description maps very well onto the composition for 'The Depressed Person' and even helps lower the probability that Wallace completed any further (missing) drafts for the story; Wallace's suggestion that his writing methods are "old-fashioned" is also significant, but I will turn to this question later on when placing Wallace's composition in a modernist context.

To return to the question of dialogical revision, having outlined the history of composition for "The Depressed Person", we can now consider the story's overall transition from the fragment (first writing phase) to the much longer drafts of the second writing phase. Wallace begins, in the subsequent drafts, by following the initial fragment very closely and only expanding the text along the lines/patterns of revision already established, in the analysis of the opening three sentences, as we can see below by continuing with the fourth sentence.

12. This practice was also employed by James Joyce (information courtesy of Finn Fordham), whose composition of Ulysses and Finnegans Wake provide major archetypes for Wallace's style of writing; as a style, this could be termed "constructivist” following Almuth Grésillon's use of the term (Grésillon 1998). 
1

She had, for instance required orthodonture, and

[...]

had to hear from each how the other was an unloving parent. 2c

The depressed person had, as a child, for instance, required orthodonture, and [...]

had to hear over and over from each parent how the other was unloving and selfish.

Both parents were well off [ . . ] it was a matter not of cash or dentition but of principle.

And the depressed person always took care to concede that so, probably it was [...].

This was just an example.

"She had" is revised to the more reiterative "the depressed person had"; the description of the parents is revised from "unloving" to "unloving and selfish"; and two new sentences are then inserted, which develop the existing story by adding detail about how the parents used their daughter as a pawn and explaining that, while they always claimed "it was a matter of principle", it was, for the depressed person herself, a kind of "neglect or outright abuse". The text then re-joins the fragment with the unaltered sentence: "This was just an example".

In a relatively clear sense, we can view Wallace as "building" with/upon the first draft at this stage. However, immediately after this sentence, the text explodes open in the second writing phase and the type of revision discussed thus far is insufficient in explaining precisely how this occurs.

In the fragment, the story of the depressed person continues in the same indirectly monological style displayed thus far, drawing to a close shortly thereafter by summarising the depressed person's response to a specific trauma as potential origin of her depression: "She never cited circumstances like these as the cause of her depression - the blame-game was too easy". The depressed person is also aware that many people endure far worse childhood traumas and do not necessarily experience depression. The fragment concludes, "In a way she would be the first to admit was perverse, she actually envied [them]", because "at least these people could 
point to something definite, at least these people could cite some sort of reason". 13

In the subsequent drafts though, the text leaps off from the fragment after the sentence "this was just an example", avoiding the original closed ending, by introducing interlocutors in the second phase of writing. These new characters become external reference points and provide the story with a new dialogical structure. These characters consist on the one hand of the depressed person's friends (or "support system", as her therapist encourages her to name/view them) and on the other, of her therapists. There is a parallel between the manner in which Wallace develops his articulation/ composition of the story and the manner in which the depressed person herself attempts to open up by communicating her pain to others. ${ }^{14}$ Either way, the story breaks out of its originally closed, monological structure, explaining who the depressed person recounts her examples of painful circumstances to:

The number of friends the depressed person reached out to for support and tried to communicate with and open up and share at least the context and texture of her unceasing pain with this way was about half a dozen and underwent a certain amount of rotation. (TS1, 1-2)

Following Wallace's dialogical innovation in the second writing phase, it is worth reflecting upon the altered relationship between the fragment and the subsequent drafts. In terms of the popular metaphor of textual con-

13. Given the basic credo of genetic criticism, that we improve our understanding of, and ability to interpret texts by learning about (textual) origins, it is interesting that the initial fragment concludes by reflecting on the complex question of origins. This question also occupied the title of the story for the majority of typescript drafts ('Provenience (or, A Depressed Person)'). In terms of the subject's depression, a simple notion of causality ("the blame-game") is clearly unhelpful.

14. To introduce a further level to this analogy, Wallace's initial fragment for "The Depressed Person" may have pre-dated the exchange with Charis Conn, which would further emphasize the manner in which its development owed something to dialogue with (or a request from) Wallace's friend and editor; it may be possible to date the fragment more precisely by matching the pen and paper to other materials in the archive, but this goes beyond the range of the current project. 
struction, the subsequent drafts no longer "build" using the initial draft in the clear or direct sense of the opening sentences. Rather than describe the entire process of composition as a type of construction, it is also important to consider the relationship between drafts as a type of dialogue; they "speak" to, but do not entirely appropriate one another, hence the process is not merely monological, it also dialogical.

Following this innovation, the introduction of separate interlocutors, the second draft initially returns to the fragment, where "the blame game was too easy", but subsequently moves on to discuss the therapists' attempts to help the depressed person, beginning with a list of medications, and the depressed person's use of her "support system". The intervention of dialogue also leads to a series of new and increasingly open endings in the subsequent versions of the story, with the depressed person eventually appealing to the most "trusted" member of her "support system" for an "honest" report on everything they have heard, in the form of an open question:

what terms might be used to describe and assess such a solipsistic, self-consumed, bottomless emotional vacuum and sponge as she now appeared to be? How was she to decide and describe-even to herself, facing herself - what all she had learned said about her? (TS2, 13)

This eventual ending provides the story with a certain modernist reflexivity. The solipsism of this internal, self-consumed reflexivity is simultaneously challenged by the external form of the question. Placed at the end or terminal point of the text, this question leaves the text open. This ending can be seen as converting each reader into an extended member of the depressed person's support system, likewise obliging readers to formulate some kind of report on the meaning of everything they have learnt throughout the course of the story; in a sense, the text becomes an extended question posed to the reader.

\section{The Afterlife of Modernism}

Many more passages from across the wealth of manuscript materials for 'The Depressed Person' warrant a detailed discussion. However, given the fact that Wallace has not been previously taken into consideration by genetic criticism, and having already established two basic types of revision in the composition of this text (loosely framed as "monological" and 
"dialogical"), I want to conclude by considering the broader significance of this work in the context of genetic criticism, as well as modernist studies.

The first type of revision, which involves a clear conception of textual construction, and which I have described as monological, is quite renowned in genetic criticism and has a strong heritage in modernism. It contains an image of the author as self-conscious craftsperson: not only constructing a text, but also, in a sense, constructing a self (or self-representation). In contrast to "organicism", an intrinsic process, an apt metaphor to describe this type of composition is "constructivism", as set out by Almuth Grésillon (Grésillon 1998); while the broader significance of this anti-essentialist term (across multiple disciplines) is relevant, the focus here is specifically upon textual construction.

As is made evident in recent work by Finn Fordham and Hannah Sullivan (Fordham 2010; Sullivan 2013), this type of composition is effectively a product of modernism. However, the boundaries that supposedly define "modernism", including its apparent obsolescence and superannuation by "post-modernism", remain less evident, and these questions are particularly relevant when it comes to contextualizing Wallace; an author writing in a so-called "post-" era yet following clearly defined modernist practices of writing. Interestingly, Hannah Sullivan actually dedicates a brief section of The Work of Revision (2013) to Wallace, entitled "The Pale King and Digital Archives". However, it should be pointed out that, in comparison to the book's main chapters on major modernist writers, the exploration of Wallace is very cursory; a minor fragment (the boy who attempts to kiss every square inch of his body) is treated as representative of a major novel and, even with respect to this fragment, no actual draft or manuscript materials are taken into consideration. Instead, Wallace is effectively used as a fall guy, with Sullivan claiming "there is no great hermeneutic difference between any of the versions because Wallace's revision process already resembles editing", suggesting that Wallace does "nothing as surprising" as the modernist revisions discussed elsewhere (in greater detail) and concluding emphatically that, "in fact, of all the revision documents that I have discussed in this book, these are the easiest and the most expected" (Sullivan 2013, 265).

I am not taking real issue with Sullivan here, as The Work of Revision does not explore Wallace in sufficient depth to support these claims more generally. The analysis provided in this essay clearly demonstrates that Wallace's revision documents do in fact contain great complexity and innovation, and are actually well placed within the context of modernism ("these acts of revision—these modernist revisions-are unpredictable 
and even unnecessary" (Sullivan 2013, 266)). I do, however, want to pursue the likely cause of Wallace's mistreatment, which seems to stem from a broader argument in The Work of Revision about a transition into a "post-modernist" era. Sullivan suggests that revision (in the modern sense) stemmed not only from modernist writing practices, but was also rooted in a particular set of historical technologies and transmission processes, which grounded those practices:

Revision is a feature of the print culture, of the modern printed book. A large number of discrete textual stages fosters rereading and reworking. [. . . The modernist practice of revision began in the service of avantgarde action, but it was perhaps also an exploration of the limit point of print culture, the final flowering of composition through documented paper stages. (Sullivan 2013, 267-9)

Sullivan therefore goes on to suggest that as society moves into a new era of digital technologies - "we have moved a long way from the print culture that sustained the modernist practice of multiple reseeding and endless revision" (Sullivan 2013, 267) — modernist revision loses its relevance:

Those who migrate to a digital world where, in Mark Poster's memorable formulation, "cultural objects have no more fixity than liquid", may find that textual revision ceases to have meaning. (Sullivan 2013, 267)

The book's limited appraisal of Wallace therefore functions as a speculative attempt to support this suggestion. This essay does not necessarily refute Sullivan's suggestion though, as Wallace could obviously be regarded as an exception: he describes his own writing methods as "old fashioned" (WALLACE, 1999). Equally, Wallace could be considered a writer working in a transitional period.

However, rather than pursue these questions, I want to consider Wallace in relation to the afterlife of modernism, a notion which the quest to establish a "post-" era easily overlooks. ${ }^{15}$ While digital technology may render cultural objects less fixed, it simultaneously enables the self — or "user" — to

15. Oddly, The Work of Revision itself overlooks the fact that the precise cultural transition in question, digitalization/computerization, is a central concern in The Pale King; hence Wallace's choice to set the novel, which is partially staged in fictional IRS offices in Peoria, in the 1980s during a period of computerization, which provokes the moral debate around tax collection (whether it should 
gain greater control over the formation of those objects. Therefore, though Marshall Boswell suggests Wallace represents a "third wave" of modernism, having broken through postmodern cynicism, without returning to pre modernist naïveté (Boswell 2003, 1-20), we could also consider Wallace as relevant for the afterlife/ongoing project of modernism in relation to the increasingly high status of "constructivism", which seems to attain the status of a new universal in post-modernist theory.

Wallace's composition of 'The Depressed Person' demonstrates a tension between a monological, self-formative, self-reflexive mode of construction and its less obvious alternate or other, dialogical innovation, which prevents the premature close of the initial fragment. There is a similar tension within the story itself, as the eponymous protagonist of the story struggles against an ever-deeper ensnarement within a solipsistic self-reflexiveness and isolation.

Just as an author's writing process or compositional practice can be seen as sharing an obscene relationship with a final text (in the etymological sense, off the stage), psychic pain can also be seen as sharing an obscene relationship with the kind of reflexivity and stream-of-consciousness associated with modernism and its famous "inward turn". ${ }^{16}$ My argument then is that, while the genetic study of Wallace reveals the afterlife of modernist modes of composition, the visible presence of psychic pain in Wallace's fiction also reveals of the perils of monologism, or a universalized "constructivism", in post-modern society. ${ }^{17}$

There is an obvious connection between solipsism and narcissism, and Mary K. Holland's chapter on Brief Interviews provides a sensitive response to this theme and the underlying question of self-representation. She writes:

'The Depressed Person' refracts the problem of narcissism and its attending threat of blocked empathy for the other through the dilemmas of the fractured self and representation, resulting in a tone so multilayered

be regarded as a human affair or a corporate one; a civic duty or a profitable business).

16. Dirk van Hulle discusses the word "obscene" in this sense in relation to genetic criticism in Manuscript Genetics (van Hulle 2008, 24-30).

17. On the rise of depression in high- and middle-income countries, see data published by the World Health Organization on the number of effective years of life lost to illness, disability or early death, where depression is now top of the list (PENm An 2011; http://www.who.int/healthinfo/global_burden_disease/); in low and very low-income countries it is approaching the top. 
that its final intention remains indeterminable, easily misread, or both. (Holland 2013, 116)

Holland connects this dilemma of "the fractured self and representation" to an underlying "problem of literature", suggesting that Brief Interviews as a whole:

Recognizes that the problem of literature is the problem of the self, and vice versa: both suffer from the necessity and prison of representation, the self forced to "look inward", to build a separate self, to "face" itself, in some ill-fated, brutally fracturing, and multiplying act of self-recognition (BI 69). (Holland 2013, 118)

The relevance of these dilemmas, not only to modernism and post-modernism, but to literature itself, makes Wallace's drive to articulate them, as echoed by the eponymous protagonist's desperate attempts in 'The Depressed Person', incredibly significant. I would suggest it also highlights the insensitivity or myopia of populist responses to such a story, which show an immediate aversion to narcissism and self-hatred..$^{18}$

Genetic criticism enables us to relate questions of the self and its representations to processes of writing. ${ }^{19}$ This essay helps unpick the aforementioned dilemmas of the fractured self and representation in 'The Depressed Person' (and its resulting tone "so multi-layered that its final intention remains indeterminable") by revealing the important and potentially unconscious role of dialogue in its development. A universalization of the self/monologue produces a potentially terrifying prison-house. Inside this totality, dialogue is reduced to a desperate appeal, as in the dangerously rhetorical question at the end of 'The Depressed Person'. I would suggest, however, that the external form of this final question opens the story up and makes it openly desirous of readerly interpretation.

18. Malcolm Knox described 'The Depressed Person' as "the most morose thing I've ever read, and that was years ago. I can't even look at it now" (KNox 2008); D. T. Max labels the story as "revenge fiction, a genre Wallace hadn't tried since 'Westward'," suggesting it was "his way of getting even with [Elizabeth] Wurtzel", and claims that the clinical symptoms of the depressed person are "revealed to be nothing more than narcissism" (MAx 2012, 241); the artist Karen Green, Wallace's wife, commented in an interview: "I read David's story 'The Depressed Person' in that book [Brief Interviews] and I thought, my God! And I wanted to make one of these pieces out of it." (Adams 2011).

19. See Fordham 2010. 
In the end, dialogue may be there all along, unbeknown to the selfforming authorial I; consider not only the role of dialogue within the story's writing process, but the role of Charis Conn, whose external call for the story encouraged Wallace's composition in the first place.

\section{Works Cited}

Adams, Tim. 2011. 'Karen Green interview', The Guardian (April 10), http://www. theguardian.com/books/2011/apr/10/karen-green-david-foster-wallace-interview.

Boswell, Marshall. 2003. Understanding David Foster Wallace. Columbia, SC: South Carolina University Press.

Boswell, Marshall, and Burn, Stephen. 2013. "Introduction". A Companion to David Foster Wallace Studies. New York: Palgrave Macmillan.

Conn, Charis. 1997. Unpublished letter to David Foster Wallace (September 30). Wallace Archive, Harry Ransom Center, University of Texas (USA), MS-5155, 27.6-7

Ferrer, Daniel. 1998. 'The Open Space of the Draft Page: James Joyce and Modern Manuscripts". In The Iconic Page in Manuscripts, Print, and Digital Culture, edited by George Bornstein and Theresa Tinkle, 249-67. Ann Arbor, MI: Michigan University Press.

- Jed Deppman and Michael Groden, eds. 2004. Genetic Criticism: Texts and Avant-Textes. Philadelphia, PA: Pennsylvania University Press, 2004.

Fordham, Finn. 2010. I do I undo I redo: the Textual Genesis of Modernist Selves. Oxford: Oxford UP.

Grésillon, Almuth. 1997. "Slow: Work in progress". Word Ë Image: A Journal of Verbal/Visual Enquiry 13 (2): 106-123.

Holland, Mary K. 2013. 'Mediated Immediacy in Brief Interviews With Hideous Men'. In Boswell 2013, 107-30.

Van Hulle, Dirk. 2009. "The Dynamics of Incompletion: Multilingual Manuscript Genetics and Digital Philology". Neohelicon 36 (2): 451-61.

- 2008. Manuscript Genetics, Joyce's Know-How, Beckett's Nohow. Gainesville: Florida University Press.

- 2013. Modern Manuscripts. London: Bloomsbury.

- 2003. Textual Awareness. Ann Arbor, MI: Michigan University Press.

Knox, Malcolm, 'Everything and More', The Monthly (November 2008), http://www. themonthly.com.au/issue/2008/november/1277253270/malcolm-knox/everythingmore

MAx, D. T. 2012. Every Love Story is a Ghost Story. New York: Granta.

PArker, Hershel. 1987. “The Text Itself'-Whatever That Is”. Text 16: 47-62.

Shillingsburg, Peter. 1996. Scholarly Editing in the Computer Age: Theory and Practice Ann Arbor, MI: Michigan University Press.

Sullivan, Hannah. 2013. The Work of Revision. Cambridge, MA: Harvard University Press. 
Wallace, David Foster. Unpublished manuscript (MS1). “A Depressed Person”. Harry Ransom Center, University of Texas (USA), MS-5155, 27.6-7.

. Unpublished typescript (TS1). "Provenience, Or: A Depressed Person". Harry Ransom Center, University of Texas (USA), MS-5155, 27.6-7.

—. Unpublished typescript (TS2). "Provenience, Or: A Depressed Person". Harry Ransom Center, University of Texas (USA), MS-5155, 27.6-7.

1999. "Brief Interview With a Five Draft Man". Amherst Magazine (Spring issue), https://www.amherst.edu/aboutamherst/magazine/extra/node/66410.

Williams, Mark, and Danny Penman. 2011. "The New Psychology of Depression”. http://podcasts.ox.ac.uk/series/new-psychology-depression.

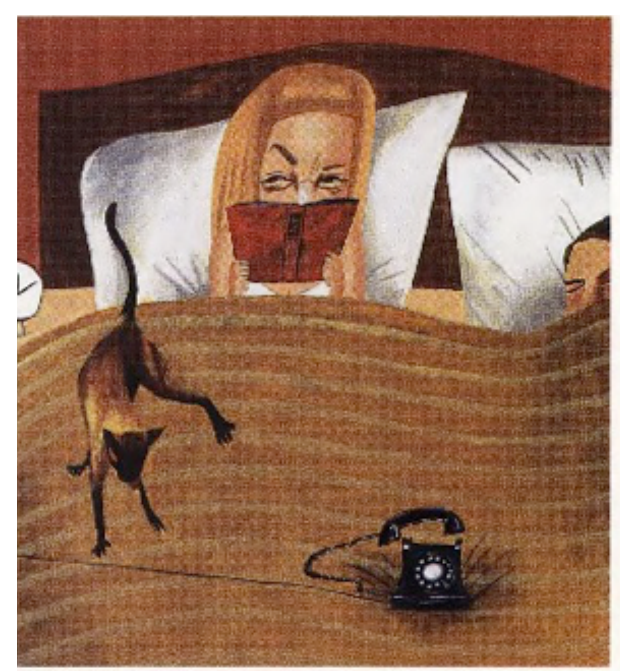

Figure 1.

Illustrations from 'The Depressed Person' in Harper's Magazine (January 1998), courtesy of Mark Ulrikse.

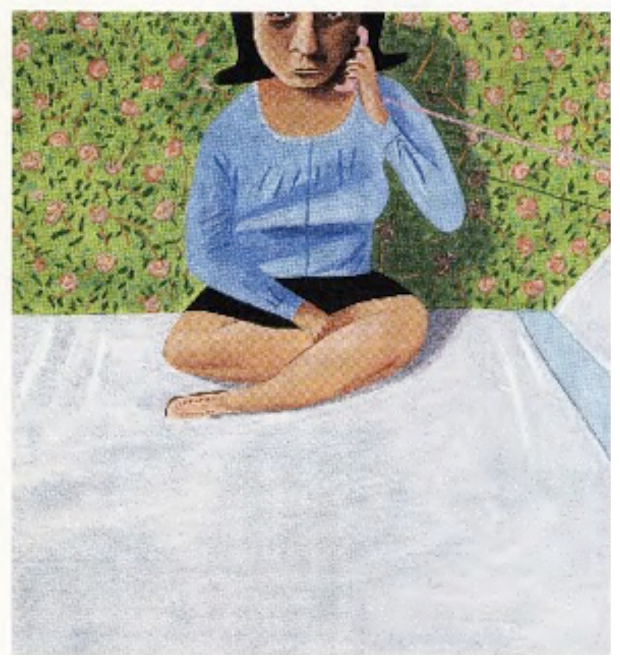

